\title{
Redução da maioridade penal no Brasil: a construção simbólica da criminalidade pela mídia
}

\author{
Carlos Eduardo Queiroz-Pessoa ${ }^{\star}$, Yldry-Souza-Ramos Queiroz-Pessoa ${ }^{\star *}$, Adilson Silva-Ferraz ${ }^{\star * *}$
}

* Mestrando do Programa de Pósgraduação em Ciências Sociais na Universidade Federal de Campina Grande (UFCG). Formado em Direito pela Faculdade de Ciências Sociais Aplicadas (FACISA). Formado em Filosofia pela Faculdade João Calvino.

Correo electrónico: carloseqpessoa@hotmail.com

** Doutoranda em Psicologia na Universidade Federal do Rio Grande do Norte (UFRN). Mestre em Saúde Pública pela Universidade Federal da Paraíba (UEPB). Professora e coordenadora do curso de psicologia na Faculdade Mauricio de Nassau em Campina Grande-рв.

Correo electrónico: yldry.souzaramos@gmail.com

$* * *$ Doutorando em Direito na Universidade de Buenos Aires (UBA). Doutorando em Filosofia na Universidade Católica Argentina (UCA). Mestre em Filosofia pela Universidade Federal de Pernambuco (UfPE). Professor auxiliar de II Universidade de Buenos Aires. Professor assistente na Faculdade Asces.

Correo electrónico:

adilson_ferraz@hotmail.com

Recibido: 27 de mayo del 2013 Aprobado: 11 de octubre del 2013

Cómo citar este artículo: Carlos Eduardo Queiroz-Pessoa, YIdrySouza-Ramos Queiroz-Pessoa \& Adilson Silva-Ferraz. Redução da maioridade penal no Brasil: a construção simbólica da criminalidade pela mídia. DIxI. Diciembre 2013. At. 63.

\begin{abstract}
Resumo
O presente estudo objetiva analisar a redução da maioridade penal como política criminal para diminuição da criminalidade juvenil. Quando crimes violentos são praticados por jovens menores de dezoito anos, a influência da mídia contribui para a construção do clamor da sociedade, voltando-se para a punibilidade como única alternativa para reprimir a violência infanto-juvenil. Assim, pretende-se rebaixar o limite de idade penal fixada em dezoito anos, a fim de submeter os menores às penalidades da legislação comum. No entanto, a menoridade penal trata-se de uma garantia fundamental atribuída aos inimputáveis, que se consubstancia ao princípio da dignidade da pessoa humana, e se configura como cláusula pétrea, de acordo com o artigo $60, \$ 4^{\circ}$, inciso IV. Não sendo, portanto, passível de Emenda Constitucional restritiva a proteção conferida aos indivíduos em processo de desenvolvimento psíquico.
\end{abstract}

Palavras-chave: cláusula pétrea, dignidade da pessoa humana, menoridade penal, punibilidade.

BAJAR LA EDAD DE RESPONSABILIDAD PENAL EN BRASIL: LA INFLUENCIA DE LOS MEDIOS DE COMUNICACIÓN EN LA CONSTRUCCIÓN DE UN CONCEPTO SIMBÓLICO DE RESPONSABILIDAD PENAL

\section{Resumen}

Este artículo intenta analizar los cambios en la política penal en aras de disminuir el crimen juvenil. Cuando jóvenes menores de dieciocho años cometen crímenes, la influencia de los medios de comunicación crea indignación, la cual conlleva a la creencia de que se debe castigar esa conducta igual que si fueran adultos como la única alternativa para frenar la violencia juvenil. De esa manera, surge un llamado para bajar la edad de responsabilidad penal actualmente fijada en dieciocho años, y que los jóvenes sean regidos por las mismas penas según la legislación común. Sin embargo, el trato diferenciado para los menores constituye una garantía fundamental que encarna el principio de la dignidad humana, expresado como la cláusula de consolidación, según el artículo $60, \S 4^{\circ}$, sección Iv. Por lo tanto, está sujeto a una enmienda constitucional restringida a la protección de los individuos durante su proceso de desarrollo psicológico.

Palabras clave: cláusula de consolidación, dignidad humana, responsabilidad penal, castigo.

Lowering the Age for Criminal Responsibility in Brazil: Media Influence in Building a Symbolic Concept of Criminal Responsibility

\section{Abstract}

This article aims to analyze changes in criminal policy aimed at decreasing juvenile crime. When violent crimes are committed by young people under the age of eighteen, the influence of the media creates indignation, leading to a belief in punishment as the only alternative for curbing juvenile violence. A call thus arises to lower the age for criminal responsibility, currently set at eighteen, and subject young people to the penalties under common legislation. However, differential treatment for minors is a fundamental guarantee that embodies the principle of human dignity, expressed as the entrenchment clause, pursuant to Article 60, $\$ 4^{\circ}$, section IV. It is therefore subject to a Constitutional Amendment restricted to protection afforded to individuals during their psychological development process.

Keywords: entrenchment clause, criminal responsibility, human dignity,, punishment 


\section{INTRODUÇÃO}

A criminalidade juvenil no Brasil ganha frequentemente repercussão pública quando menores de dezoito anos cometem crimes violentos contra a vida. Diante disso, a preocupação em torno da modificação da idade penal apresenta-se como política criminal cada vez mais difundida no país, a ser instituída para a repressão da delinquência que envolve adolescentes, uma vez que a mídia acaba enfatizando de forma veemente que os índices de violência estão associados à inegável participação de adolescentes na prática de delitos. Com relação à criminalidade que envolve menores, crescem as opiniões acerca da mudança na legislação brasileira quanto à redução da imputabilidade penal, o que confere nova redação ao artigo 228 da Constituição Federal de 1988. Existem no Congresso Nacional cerca de vinte e nove propostas de emenda à Constituição elaboradas para viabilizar a modificação da faixa etária de responsabilização penal, visto que os menores estão sujeitos à legislação especial (Estatuto da Criança e Adolescente -ECA), cumprindo medidas socioeducativas, por serem considerados inimputáveis.

O debate sobre possíveis modificações da idade de imputabilidade penal tem como pressuposto a diminuição da violência juvenil no país que se utiliza da reprimenda penal. Essa iniciativa ganha adeptos sob o argumento de que os menores estão inseridos em um contexto sociocultural de amplo acesso a informações, o que antecipa a maturidade intelectual para compreenderem o caráter ilícito de suas condutas. No entanto, deve-se considerar que a criminalidade no contexto social brasileiro está relacionada às classes pobres, situadas nas periferias constituídas, basicamente, de pobres, negros e analfabetos. E que essa estigmatização aprofundou-se com o discurso ideológico da mídia e favoreceu, assim, aos interesses da elite econômica, que, incomodada com a delinquência urbana, tornase a favor de uma política criminal severa sempre mais punitiva e repressora.

\section{A MÍDIA E CRIMINALIDADE}

A imprensa, atualmente, constitui-se como um instrumento do capitalismo, o qual possibilitou que empre-

$1 \mathrm{O}$ presente é um artigo de reflexão, resultado da pesquisa terminada e vinculada à linha de Sociologia do Direito da UFPB. sas de telecomunicações se tornassem organizações multinacionais a serviço da expansão do mercado financeiro globalizado. Diante disso, o desenvolvimento das novas tecnologias de transmissão de informações a longas distâncias passou a ser financiado pelas grandes corporações empresariais. Estas propiciaram a criação dos canais de comunicação direcionados ao mercado de notícias, tendo o capitalismo transformado a cultura da informação em mercadoria, o que deu origem à indústria da mídia, sediada nos Estados Unidos e em parte da Europa, passando os sistemas de comunicação transnacionalizados a fornecer serviços destinados à promoção de propagandas, essencialmente comerciais. ${ }^{1}$ Desde a Segunda Guerra Mundial, as quatro maiores agências (Reuters, Assocated Press [AP], Agence France-Presse [AFP] e a United Press Association [UPA]) passaram a assumir posições de liderança na organização global de informações jornalísticas e radiotelevisivas, o que construiu o padrão de notícias transmitidas globalmente e submeteu os países mais pobres à indústria cultural dominada pelos temas publicitários de caráter, fundamentalmente, econômicos, que disseminam o estilo de vida consumista produzido pelo mercado imperialista do capitalismo hegemônico.

A influência do poder econômico nos interesses defendidos pela mídia direciona suas informações e imagens para a conquista do domínio do mercado consumidor:

Não devemos olvidar que existe uma concorrência selvagem entre os veículos de comunicação pela conquista dos mesmos "clientes": anunciantes e público consumidor. A partir da lógica de mercado dominante, informação passa a ser um bem informacional, uma mercadoria. A busca pelo aumento da audiência e de circulação, a necessidade de atingir o maior número de pessoas, resultam na simplificação e esquematização de temas complexos, na consagração de uma visão maniqueísta do mundo. Além da questão mercadológica, essas escolhas editoriais também são pautadas pela hegemonia atual da televisão sobre os outros meios, o que implica a construção de narrativas baseadas na emoção e na força das imagens. Para esse jornalismo de resultados, saber, conhecimentos, reflexão, entendimento, atividades que exigem um tempo que não pode ser comparado ao dinheiro, transformam-se em meros figurantes. O protagonista é a notícia que vende, que mantém uma marca em evidência. ${ }^{2}$

2 C. Batch. Mídia, crime e responsabilidade. Revista de Estudos Criminais. 2001. Pág. 97. www.itecrs.org/revista/1.pdf. (10 abril 2011). 
Como se observa, a mídia televisionada consolidou-se como veículo de transmissão utilizado pelo poder econômico das grandes corporações, tendo em vista a alta lucratividade que proporciona o mercado de publicidade. Consequentemente, utiliza seu poder de convencimento em vista do retorno financeiro de acordo com as notícias que captem a atenção dos consumidores e promovam a audiência.

Em defesa dos interesses do capital, a mídia muitas vezes transmite valores para a sociedade como verdades inquestionáveis, o que interfere na maneira de pensar da população pela produção de informações visuais e auditivas, tendo forte influência na construção da conscientização dos telespectadores acerca da realidade noticiada. É capaz de despertar a atenção dos telespectadores pelo espetáculo das imagens e gerar, assim, altos níveis de audiência com a finalidade de comover a opinião pública, ao homogeneizar as ideias e forjar a verdade relacionada a determinados fatos, de modo a criar um consenso aceito pela sociedade. A mídia com o poder tecnológico de transmitir as informações em larga escala, manipula-as em proveito de seus próprios interesses, mesmo que aparentemente se demonstre em defesa da sociedade. A ideologia define-se como "[...] um sistema de ideias que expressa os interesses da classe dominante, mas que representa relações de classe de forma ilusória." 3 Porquanto, ao despontar a serviço de poucos grupos empresariais, a imprensa televisiva torna-se onipresente na vida da população, independentemente de classe social, que usufrui deste meio de comunicação como sendo uma das únicas fontes seguras de confiar nas informações com veracidade.

No Brasil, a concentração da mídia encontra-se sob o controle da iniciativa privada de nove famílias, Marinho, Bloch, Santos, Saad, Frias, Mesquita, Levy, Civita e Nascimento Brito. Esses grupos manipulam o conteúdo das informações em cerca de noventa por cento de tudo o que os brasileiros leem, ouvem e veem através dos meios de comunicação de massa, com forte influência na formação da opinião pública.

Se é a comunicação que constrói a realidade, quem detém a construção dessa realidade detém também o poder sobre a existência das coisas, sobre a difusão das ideias, sobre a criação da opinião pública. Mas não é só isso. Os que detêm a comunicação chegam até a definir os outros, definir determinados grupos sociais como

3 J. B.Thompson. A mídia e a modernidade: uma teoria social da mídia. 11. ed. Pág. 54. Ed. Vozes. (2009). sendo melhores ou piores, confiáveis ou não confiáveis, tudo de acordo com os interesses dos detentores do poder. ${ }^{4}$

As agências de telejornalismo passaram a difundir a criminalidade como discurso ideológico relacionado à pobreza. $\mathrm{O}$ enfoque sensacionalista dado à criminalidade pela mídia alimenta a cultura do medo e leva a considerar que o crime é uma forma de entretenimento rentável. Desse modo, a notícia elabora um perfil do criminoso quase sempre identificado com as características das pessoas pobres e trabalhadoras, situadas nas regiões socialmente mais precárias da realidade urbana. ${ }^{5}$ Deve-se então compreender que o interesse na propagação da criminalidade e da insegurança provoca a intervenção estatal, por meio da repressão policial e da elaboração de uma legislação cada vez mais punitiva, o que nutre a cultura do medo com amplo apoio da mídia. Esta submete a sociedade a um clima de insegurança e intensa propagação de informações telejornalíticas que envolvem a criminalidade: "[...] a paranoia, o medo e a sensação de insegurança interessam somente aqueles que exploram o crime, seja de que maneira for, interessam apenas àqueles que não estão interessados em resolver os verdadeiros motivos da violência, aos que usam a desculpa de violência para serem violentos." ${ }^{3}$ Destarte, o discurso produzido pela impressa acerca da criminalidade gera uma sensação de insegurança que afeta a sociedade e reconfigura, assim, o modo de vida urbano brasileiro.

É diante desse cenário que a sociedade urbanizada se integrando de maneira desigual define a organização territorial construída entre ricos e pobres, sobretudo, ao considerar a realidade das grandes cidades brasileiras. Nessa segregação espacial, acontece a propagação da insegurança, tornando-se a mídia o dispositivo cultural mais influente na formação da opinião pública. A emissão das notícias sobre a criminalidade choca e comove a sociedade, que inflacionando a sua percepção sobre os riscos da realidade urbana, diante da discrepante situação de desigualdade social, aumenta o foco de preocupação quanto à necessidade de reprimir a violência criminal. Cria-se, então, um consenso público de repressão punitiva às condutas delitivas que

4 P. A. Guareschi ET AL. Os construtores da informação: meios de comunicação, ideologia e ética. 2. ed. Pág. 43. Ed. Vozes. (2007).

5 L. F. Baierl. Medo social: da violência visível ao invisível da violência. Ed., Cortez. (2004).

6 E. L. E. Silva. De beccaria a filippo gramatica: ciência e política criminal em honra de Heleno Fragoso. Pág. 23. Ed. Forense. (1993). 
afetam os cidadãos, mormente, quando praticadas nas localidades mais nobres das cidades.

A população rica situada nos bairros residenciais servidos das melhores áreas urbanas das cidades, fechada em condomínios luxuosos, desfrutando do alto padrão de consumo, que o poder econômico lhe garante, sentindo-se ameaçada pela criminalidade, reclama por medidas mais eficazes de proteção estatal. Em contrapartida, os pobres submetidos a condições de vida, muitas vezes em situação de miséria, encontramse confinados nas periferias e comunidades, figurando como os principais sujeitos da criminalização, a partir da realidade construída pela mídia, que se utiliza de informações e imagens selecionadas para criar o noticiário criminal, gerando o clamor público. Diante desse paradoxo, "este tipo de comunicação não se limita a proporcionar uma falsa imagem da realidade, mas produzir a própria realidade." Para atender-se ao clamor público, exige-se um maior endurecimento no aparato repressivo no combate à criminalidade. Por conseguinte, causando distorções comportamentais na sociedade, o jornalismo constrói discursos para justificar sua legitimidade manipulando informações desprovidas de uma profunda reflexão sobre o fenômeno da criminalidade, alimentando a cultura do medo através da criação de um contexto social de riscos, que ameaça a segurança e a ordem pública.

O reconhecimento do papel político do jornalismo, porém, obviamente não lhe confere o direito de substituir outras instituições. Apesar disso, é notório que a imprensa vem procurando exercer funções que ultrapassam de longe o seu dever fundamental, assumindo frequentemente tarefas que caberiam à polícia ou à justiça. E essa invasão de espaços pode ser considerada justamente a partir de uma definição cara à imprensa: a qualificação de "quarto poder" que data do início do século XIX e lhe confere o status de guardiã da sociedade (contra os abusos do Estado), representante do público, voz dos que não tem voz. É certamente sustentada por esta visão mistificadora - porque encobrida dos interesses da empresa jornalística, desde sua constituição, há dois séculos, e especialmente agora na era das grandes corporações que a imprensa se arroga o direito de penetrar em outras áreas. ${ }^{8}$

7 E. R. Zaffaronni. Em busca das penas perdidas: a perda de legitimidade do sistema penal. Pág. 131. Ed. Revan. (1991).

8 S. Moretzsohn. O caso Tim Lopes: o mito da "mídia cidadã". www.bocc. ubi.pt/pag/moretzsohn-sylvia-tim-lopes.pdf. (25 março 2011).
Assim, o poder da indústria de notícias, ao exercer seu dever de esclarecer a sociedade, estimula políticas públicas de controle à criminalidade por meio de medidas repressivas e dificilmente preventivas. Ainda que se valendo da imparcialidade e da transparência, propaga a ideologia da política econômica que representa o processo de criminalização em que grupos poderosos conseguem influenciar na política criminal do Estado.

As teorias conflituais da criminalidade afirmam que: a) os interesses que estão na base da formação e da aplicação do direito penal são os interesses daqueles grupos que têm o poder de influir sobre os processos de criminalização - os interesses protegidos através do direito penal não são, pois, interesses comuns de todos os cidadãos; b) a criminalidade, no seu conjunto, é uma realidade social criada através do processo de criminalização. Portanto, a criminalidade e todo direito penal têm, sempre, natureza política. ${ }^{9}$

Embora saibamos que o problema da criminalidade não se resume apenas à influência proveniente da indústria cultural, devemos considerar que os legisladores, na elaboração das leis penais, encontram-se inseridos nesse processo de manipulação da informação e construção simbólica da criminalidade.

Não se pode negar que a delinquência juvenil é um fenômeno presente na sociedade brasileira e que, consequentemente, necessita de atenção do Estado em vista de assegurar-se a pacificação social. Desse modo, o tema da redução da maioridade penal, que visa conferir nova redação ao artigo 228 da Constituição Federal de 1988, pauta-se como uma alternativa, amplamente difundida pela mídia para responsabilização dos adolescentes após crimes que movimentam a opinião pública. Sugere-se a repressão penal como política punitiva para a diminuição da violência criminal pela penalização de práticas delituosas envolvendo jovens. No entanto, é preciso desmistificar soluções simples e imediatistas propagadas pelos sistemas de comunicação em face de problemas complexos que afligem a sociedade, tendose em vista que a mídia elabora a realidade, geralmente, a partir de fatos isolados com forte apelo emocional, que se transformam em notícias sensacionalistas para a obtenção de audiência e lucratividade na conquista de clientes no mercado do telejornalismo.

\footnotetext{
9 A. Barata. Criminologia crítica e crítica do direito penal: introdução à sociologia do direito penal. Tradução Juarez Cirino dos Santos. 3. ed. Pág. 119. Ed. Revan. (2002).
} 


\section{MAIORIDADE PENAL COMO CLÁUSULA PÉTREA}

A reflexão sobre a maioridade penal é sempre suscitada quando crimes violentos que chocam a sociedade são praticados por jovens, tornando-se a mídia eletrônica um dos principais veículos de informação para a construção de uma opinião pública, constituída a partir do forte apelo sensacionalista. O impacto das informações se propaga de tal modo que influencia na formação da opinião da sociedade e cria, portanto, um ambiente de comoção coletiva que leva a acreditar-se que o rebaixamento da idade penal é uma das únicas alternativas de política criminal viáveis para a diminuição da criminalidade infanto-juvenil.

É dado grande destaque nos meios de comunicação a atos de violência cometidos por (ou mesmo muitas vezes apenas supostamente atribuídos) a crianças e jovens, geralmente pobres, destaque esse seguido frequentemente pela crítica ao ECA e pela defesa da redução da idade penal como principal alternativa frente ao suposto crescimento da criminalidade infantil e juvenil. ${ }^{10}$

A reflexão sobre o ingresso dos jovens no universo da delinquência muitas vezes não leva em consideração a realidade social de pobreza a que está submetida a maioria da população juvenil. Dados relevantes demonstram que os jovens no Brasil são o grupo mais afetado pelos homicídios, principalmente, os do sexo masculino, o que revela um dramático crescimento, nos últimos 15 anos, nos assassinatos perpetrados contra crianças e adolescentes, que vivem em precárias condições de vida no país. Por isso, resulta-se sustentar que:

[...] os adolescentes são muito mais vítimas de crimes do que autores, contribuindo esse fato para a queda da expectativa de vida no Brasil, pois se existe um "risco Brasil", este reside na violência da periferia das grandes e médias cidades. Dado impressionante é o de que $65 \%$ dos infratores menores vivem em família desorganizada, junto com a mãe abandonada pelo marido, que por vezes tem filhos de outras uniões também desfeitas, e lutam para dar sobrevivência à sua prole. ${ }^{11}$

10 M. C. Alvarez. Menoridade e delinqüência: uma análise do discurso jurídico e institucional da assistência e proteção aos menores no Brasil. Cadernos da FFC (Unesp). 1997. Pág. 24.

11 M. Reale Júnior. Instituições de Direito Penal: parte geral. 3. ed. Pág. 213. Ed. Forense. (2009).
O Brasil em 1999 ocupava a terceira posição quando se tratava dos homicídios referentes aos jovens, com índices de 48,5 homicídios por cem mil habitantes, e encontra-se altamente distante dos países que obtinham médias abaixo de 1 homicídio por 100 mil jovens. Estatísticas ainda de 1995 apontavam que na faixa etária dos 10 aos 29 anos de idade, os índices alcançavam 32,5 por 100 mil habitantes. Em 1998, a faixa dos 15 aos 24 anos, o índice foi de 26,3 homicídios por cem mil habitantes, verificando-se uma situação que, portanto, revela as crianças e os adolescentes como a parcela da sociedade que mais está propensa à exposição da violação de direitos, seja pelo Estado, pela sociedade e pela família. ${ }^{12}$

Uma melhor evidência sobre o significado dessa vitimização pode ser obtida comparando a evolução diferenciada das taxas de homicídio da população jovem e da não jovem ao longo do tempo. No ano de 1980, foram registrados 27.464 homicídios dos quais 7.524 corresponderam a jovens e 19.940 a não jovens. Para o ano 2002, foram registrados 49.413 homicídios dos quais, 19.124 foram jovens e 30.289 no resto da população. Relativizando esses dados segundo população, teríamos que a taxa de homicídios entre os jovens passou de 30,0 (em 100.000 jovens) em 1980 para 54,5 no ano 2002. Já a taxa no restante da população (não jovem) permaneceu praticamente inalterada: passou de 21,3 em 100.000 para 21,7 no mesmo período. Isso evidencia, de forma clara, que os avanços da violência homicida no Brasil, das últimas décadas, tiveram como eixo exclusivo a vi-

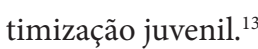

Mesmo diante dessas circunstâncias, as informações são veiculadas passando-se a ideia de que a criminalidade juvenil cresce e os crimes graves estão sempre aumentando, o que cria um imaginário popular que se faz necessário punirem-se penalmente os adolescentes. Torna-se imperioso constatar-se que a situação da juventude brasileira é grave e que se encontra mais na posição de vítima do fenômeno da violência urbana, que, dada à devida importância ao combate a crimes praticados por jovens, as autoridades brasileiras priorizam o direito penal e a repressão policial no enfrentamento à criminalidade. Ao revelar que "[...] estas propostas refletem reações emocionais e imediatistas, causadas pelo

12 M. Volpi. Sem liberdade, sem direitos: a privação de liberdade na percepção do adolescente. Ed., Cortez. (2001).

13 J. J. Waiselfisz. Mapa da violência IV: os jovens do Brasil. Pág. 73. Ed., Unesco, Instituto Airton Senna. Secretaria Especial dos Direitos Humanos. (2004). 
desespero decorrente da crise da segurança pública e da alta taxa de criminalidade."14 Ademais, por vezes, o poder público esquece que as péssimas condições de vida da sociedade caracterizam-se como um dos principais motivos dos altos índices de violência.

A redução da maioridade penal não é a solução para os problemas derivados da criminalidade infantil, visto que o cerne do problema da criminalidade se reluz em decorrência das condições socialmente degradantes e economicamente opressivas que expõe enorme contingente de crianças e adolescentes, em nosso país, à situação de injusta marginalidade social. ${ }^{15}$

Ao não haver priorização das políticas públicas que são instrumentos capazes de melhorar, socialmente, a qualidade de vida de parte da população pobre, por meio da disponibilização do acesso adequado a bens fundamentais como educação, saúde, moradia, emprego e lazer, é impossível não concordar que "[...] querer rebaixar a idade penal não passa de uma proposta de apelo fácil para dar uma satisfação à opinião pública, é uma demonstração de quem não tem política social." ${ }^{16}$

No ordenamento jurídico pátrio vigente, o patamar etário de responsabilidade penal foi estabelecido com o advento do Código Penal Brasileiro de 1940, depois de a configuração do sistema penal sofrer grande influência estrangeira e fixar a imputabilidade em dezoito anos. Essa iniciativa ocorreu baseada em uma política criminal que, apesar de objetivar a inserção na esfera punitiva condutas lesivas ao interesse social, acabou optando por instituir tratamento diferenciado aos menores abaixo da idade fixada legalmente, o que prevê proteção especial e torna-os inimputáveis, ou seja, não se responsabiliza criminalmente o menor de dezoito anos, conforme previsto no artigo 27 do Código Penal, “[...] os menores de dezoito anos são penalmente inimputáveis, ficando sujeitos às normas estabelecidas na legislação especial." ${ }^{17}$

Nesse sentido, com a promulgação da Constituição Federal de 1988, seguindo as orientações internacionais, por meio da Organização das Nações Unidas

14 F. Piovesan. A inconstitucionalidade da redução da maioridade penal. www.direitocriminal.com.br. (16 de outubro 2011).

15 J. F. Mirabete. Manual de direito penal: parte geral, v. 1. 27 ed. Pág. 217. Ed. Atlas. (2012).

16 A. Queirós. Por que não à redução da idade penal? In: Fórum permanente de entidades não-governamentais de defesa dos direitos da criança e do adolescente. Infância, ato infracional e cidadania. Pág. 31. Ed. Inesc. (1999).

17 Brasil. Vade Mecum Saraiva. 6. ed. Pág. 74. Ed., Saraiva. (2012).
(ONU), patrocinando mundialmente a tutela dos direitos das crianças e dos adolescentes de acordo com as prerrogativas determinadas pela Convenção sobre os Direitos da Criança, o constituinte pátrio determinou, segundo o artigo 228 da Carta Magna, que "são penalmente inimputáveis os menores de 18 anos, sujeitos às normas da legislação especial."18

A pretensão de redução viola o disposto no artigo 41 da Convenção das Nações Unidas de Direito da Criança, onde está implícito que os signatários não tornarão mais grave a lei interna de seus países, em face do contexto normativo da Convenção, a qual se faz lei interna de caráter constitucional, conforme o $\$ 2^{\circ}$ do artigo $5^{\circ}$ da Constituição Federal. ${ }^{19}$

A legislação especial específica da infância e juventude que regulamenta a Constituição Federal e a qual se refere o Código Penal foi constituída a partir do ECA, Lei Federal 8.069/1990, que trata a criança e o adolescente como sujeitos de direitos e impede de serem submetidos à persecução penal, ao aplicar-lhes medidas de proteção e preservar a condição de pessoas em processo de desenvolvimento mental. O ECA considera como criança a pessoa de até doze anos de idade incompletos, e adolescentes entre doze e dezoito anos de idade, definição do seu artigo $2^{\circ}$. Ao presumir-se que são penalmente inimputáveis os menores de 18 anos, previsão do parágrafo único do artigo 104, visto que "[...] o adolescente, como pessoa que ainda vive o processo de amadurecimento físico, psicológico e emocional, merece além de uma simples censura e castigo da sociedade, a oportunidade de, através das medidas pedagógicas, mudar seu comportamento." ${ }^{20}$

Com a fixação desse patamar etário mínimo para a imputabilidade penal, optou-se por conferir direitos inerentes à pessoa humana aos menores de dezoito anos em relação à lei especial, tratando-se de "[...] verdadeira garantia individual da criança e do adolescente em não serem submetidos à persecução penal em Juízo, tampouco poderem ser responsabilizados criminalmente, com consequente aplicação de sanção penal." ${ }^{21}$

18 Brasil. Vade Mecum Saraiva. 6. ed. Pág. 74. Ed., Saraiva. (2012).

19 M. A. Geske. Imputabilidade do Adolescente no Direito Penal. Revista da ESMESC. 2007. Pág. 226.

20 G. R. M. M. Simões. A redução da idade de responsabilidade penal solucionaria o problema da violência? Revista Jurídica da Universidade de Franca: Unifran. maio 2001. Pág. 79.

21 A. Moraes. Constituição do Brasil interpretada e legislação constitucional. 8. ed. Pág. 2.036. Ed. Atlas. (2012). 
Diante disso, o tema referente à inimputabilidade penal antes dos dezoitos anos consubstanciou-se matéria de direito fundamental previsto no próprio texto constitucional, visando-se à devida proteção dos direitos e garantias às crianças e aos adolescentes, enquanto pessoas em fase peculiar de desenvolvimento psíquico. Decorre-se que os adolescentes se encontram em condição privilegiada juridicamente e necessitam de proteção e tutela assistencial adequadas para crescerem e se desenvolverem, respeitando-os como pessoas ainda em formação.

Nesse contexto, a Constituição de 1988, com o artigo 227, consagrou a Doutrina da Proteção Integral para as crianças e os adolescentes, que passaram a ser sujeitos de proteção e de reconhecidos direitos fundamentais, como o direito à vida, à saúde, à alimentação, à educação, ao lazer, à profissionalização, à cultura, à dignidade, ao respeito, à liberdade e à convivência familiar e comunitária, cabendo à família, à sociedade e ao Estado a proteção e promoção desses direitos indispensáveis à pessoa em contínuo processo de amadurecimento humano. Dando-se prioridade absoluta para o desenvolvimento integral e sadio das crianças e dos adolescentes, há uma garantia de natureza pessoal embutida no artigo 228 , que estando incorporado ao artigo $5^{\circ}$ como forma de proteção, vincula-se ao princípio da dignidade da pessoa humana. Tendo o legislador constituinte, com a consolidação dos direitos humanos a partir do século $\mathrm{xx}$, estendido às crianças e aos adolescentes vários direitos fundamentais, já materializados no âmbito internacional. "Recordando que na Declaração Universal dos Direitos Humanos, as Nações Unidas proclamaram que a infância tem direito a cuidados e assistência especiais." 22 Decerto, a tentativa de responsabilizar, penalmente, as crianças e os adolescentes contraria um direito fundamental, porque consiste em uma garantia individual do cidadão, assegurada, constitucionalmente, como insusceptível de modificação. Integrando-se ao núcleo irreformável na condição de cláusula pétrea, de acordo com a previsão do $\$ 4^{\circ}$, inciso IV, do artigo 60 da Constituição, que veda qualquer possibilidade de proposta tendente a abolir ou restringir direito ou garantia, a não ser por constituinte originária. Embora o artigo mencionado não esteja incluído entre os dispositivos previstos no artigo $5^{\circ}$ da Carta Magna, trata-se de direito de natureza análo-

22 Brasil. Convenção internacional sobre os direitos da criança. 2008. http://www.mpmg.gov.br.extranet/visao/sigecon/html/uploads/html_ proprio/html_7621/.(16 novembro 2011). ga, uma vez que o rol do Título II, que prevê em especial o rol de direitos e garantias individuais, não é exaustivo e nem taxativo, existindo outros dispersos ao longo do texto constitucional e reconhecidos expressamente como fundamentais. Com isso, o constituinte considerou os elementos constantes do $\$ 4^{\circ}$, do artigo supracitado, como integrantes da identidade constitucional, que, pela grande relevância, gravou-os com a cláusula de imutabilidade. Portanto, os direitos fundamentais:

[...] não são somente aqueles expressamente declarados na Constituição e nas leis, mesmo porque o legislador constituinte originário foi bem precavido ao dizer no $\$ 2^{\circ}$ do art. $5^{\circ}$ que os direitos e garantias expressos nesta Constituição não excluem outros decorrentes do regime e dos princípios por ela adotados, ou dos tratados internacionais em que a República Federativa do Brasil seja parte..$^{23}$

Como o constituinte não elencou expressamente os direitos e garantias individuais, pode-se concluir que somente por meio de interpretação estes serão identificados. Dessa maneira, a regra do artigo 228 da Constituição garante o respeito aos direitos individuais e a promoção da dignidade humana, ao revestir-se de reconhecimento jurídico da proteção integral aos menores de dezoito anos de idade, por estarem em condições de hipossuficiência.

Os direitos fundamentais, de acordo com a concepção contemporânea, constituem decisões axiológicas consensualmente aceitas, que do ponto de vista histórico incidem sobre todo o ordenamento jurídico como normas objetivas de base principiológica. E a finalidade das cláusulas pétreas é preservar os princípios constitucionais, incorrendo-se grande risco interpretá -las restritivamente.

Essa afirmação simplista, ao invés de solver o problema, pode agravá-lo, pois a tendência detectada atua no sentido não de uma interpretação restritiva das cláusulas pétreas, mas de uma interpretação restritiva dos próprios princípios por elas protegidos. Essa via, ao invés de permitir um fortalecimento dos princípios constitucionais contemplados nas garantias de eternidade, como pretendido pelo constituinte, acarreta, efetivamente, o seu enfraquecimento. Assim, parece recomendável que eventual interpretação restritiva se

23 N. Slaib Filho. Direito Constitucional. Pág. 379. Ed. Forense. (2004). 
refira à própria garantia de eternidade sem afetar os princípios por ela protegidos. ${ }^{24}$

Conforme a tendência internacional de valorização da adolescência, fase especial de desenvolvimento dos seres humanos, no entendimento do Supremo Tribunal Federal, assentou-se que as garantias constitucionais não se limitam ao artigo $5^{\circ}$ da Constituição Federal. "Assim, o art. 228 da Constituição Federal encerra hipótese de garantia individual prevista fora do rol exemplificativo do art. $5^{\circ}$, cuja possibilidade já foi declarada pelo STF em relação ao art. 150, III, b (Adin 939-7/DF - conferir comentários ao art. $5^{\circ}, \$ 2^{\circ}$ ) e, consequentemente, autêntica cláusula pétrea prevista no art. $60, \S 4^{\circ}, I^{\prime \prime} .{ }^{25}$ Esse tratamento jurídico diferenciado em relação aos adultos sobrevém pelo fato de os menores de dezoito anos serem sujeitos portadores de um direito fundamental, que diante do disposto no artigo 60, $\$ 4^{\circ}$, da Constituição Federal de 1988, tratase, pois, de limites materiais que representam o "[...] conjunto de preceitos integrantes da Constituição que não podem ser objeto de emenda constitucional restritiva." ${ }^{26}$ Assim, o legislador constitucional incorporou tratamento especial às crianças e aos adolescentes, como pessoas em desenvolvimento, atribuindo-lhes direitos fundamentais, que estão expressamente previstos nos artigos 227 e 228 da Constituição, representando garantias individuais decorrentes dos direitos assegurados aos menores. Ao estabelecer a idade mínima de imputabilidade penal, a norma inscrita no artigo 228 do texto constitucional, integra o núcleo imodificável da Carta Política, de maneira que:

[...] nesse terreno movediço em que falta razão, só mesmo a natureza pétrea da cláusula constitucional (artigo 228) que estabelece a idade penal resiste ao assédio do conservadorismo penal. A inimputabilidade etária, muito embora tratada noutro capítulo que não aquele das garantias individuais, é sem dúvida um princípio que integra o arcabouço de proteção da pessoa humana do poder estatal projetado naquele e assim deve ser considerado cláusula pétrea (artigo $5, \$ 2^{\circ}$ ). No mesmo

24 G. F. Mendes. Os Limites da Revisão Constitucional. Revista Notícia do Direito Brasileiro. 1996. Pág. 188.

25 A. Moraes. Constituição do Brasil interpretada e legislação constitucional. 8. ed. Pág. 2.036. Ed. Atlas. (2012).

26 A. R. Tavares. Curso de direito constitucional. 9. ed. Pág. 54. Ed. Saraiva. (2011) sentido, leva a Convenção sobre os Direitos da Criança da ONU..$^{27}$

As matérias incluídas nas cláusulas de irreformabilidade do artigo $60, \$ 4^{\circ}$, incisos de I ao IV, são improponíveis no Congresso Nacional, decorrendo-se que qualquer tentativa do legislador infraconstitucional de abolir do texto constitucional a fixação da idade penal ou que pretenda reduzir a idade de responsabilização penal será, flagrantemente, inconstitucional, estando vedada pela própria Constituição, a fim de pretende-se preservar núcleos essenciais de direitos que devem ser mantidos por caracterizar a própria Lei Maior.

\section{REDUÇÃO DA IMPUTABILIDADE PENAL}

No Brasil, atualmente, a violência com o envolvimento de jovens na criminalidade torna-se um problema que repercute na insegurança da ordem pública, existindo inúmeras Propostas de Emendas Constitucionais que tramitam no Congresso Nacional, visando à modificação de matéria de ordem constitucional para reduzir a idade de responsabilidade penal. ${ }^{28}$ As propostas pretendem responsabilizar criminalmente os menores de 18 anos, ao aplicar-lhes uma justa punição de maneira a imputar aos jovens delinquentes penalidades equivalentes, proporcionalmente, ao delito praticado, almejando-se a diminuição dos níveis de violência infanto-juvenil.

A redução do patamar etário penal poderia acarretar uma redução da violência, visto que o jovem criminoso seria punido com a pena correspondente ao delito praticado, proporcionando, assim, uma justa punição aos jovens delinquentes. É possível até mesmo se aventar a hipótese de descabimento do tratamento dado ao menor, porque isso feriria o princípio da proporcionalidade da pena, segundo o qual a pena tem que ser proporcional à lesão causada, e uma internação máxima de três anos para casos de crimes como homicídio seria demasiadamente branda. ${ }^{29}$

27 J. B. C. Saraiva. A idade e as razões: não ao rebaixamento de imputabilidade penal. Revista Brasileira de Ciências Criminais. abriljunho 1997. At. Pág. 91.

28 M. S. da. Campos. Mídia e política: a construção da agenda nas propostas de redução da maioridade penal na câmara dos deputados. Opinião Pública. novembro, 2009. Pág. 478-509. http://www.scielo.br/scielo.php?pid=S010462762009000200008\&script=sci_arttext. (17 novembro 2011).

29 C. E. B. Rebelo. Maioridade penal e a polêmica acerca de sua redução. Pág. 22. Ed., Ius Editora. (2010). 
Os defensores da redução da maioridade penal sustentam vários argumentos para justificar a necessária modificação da Carta Magna, quanto ao conteúdo do seu artigo 228, consoante proposta de Emenda no plano jurídico constitucional. Nessa linha, existe quem defenda que "[...] sendo o artigo 228, matéria de ordem constitucional, sua alteração seria perfeitamente possível, somente por meio de emenda constitucional que possa alterar o dispositivo em questão, conforme preceitua o disposto no artigo 60 da Carta Maior." ${ }^{30}$ Nesse itinerário, é relevante apresentar sustentação que não considera inconstitucional a redução, consoante se delineia nas seguintes ilações:

[...] embora parte da doutrina entenda, a nossa posição pessoal é no sentido de ser perfeitamente possível a redução de 18 para 16 anos, uma vez que apenas não se admite a proposta de emenda (PEC) tendente a abolir direito e garantia individual. Isso não significa, como já interpretou o STF, que a matéria não possa ser modificada. Reduzindo a maioridade penal de 18 anos para 16 anos, o direito à inimputabilidade, visto como garantia fundamental, não deixará de existir. A sociedade evoluiu e, atualmente, uma pessoa com 16 anos de idade tem total consciência de seus atos, tanto é que exerce os direitos de cidadania, podendo propor a ação popular e votar. Portanto, em nosso entender, eventualmente a PEC que reduza a maioridade penal de 18 para 16 anos é totalmente constitucional. O limite de 16 anos já está sendo utilizado e é fundamental no parâmetro do exercício do direito de votar e à luz da razoabilidade e maturidade do ser humano. ${ }^{31}$

A controvérsia da redução da maioridade penal situa-se quanto à possibilidade do marco etário integrar-se ou não entre os direitos e garantias individuais, consubstanciando-se analogamente às cláusulas pétreas, que por força do artigo $60, \$$, inciso IV da Constituição Federal, tornar-se-ia imutável e insusceptível de qualquer proposta de alteração via emenda constitucional. Embora entendendo que a redução da idade penal não resolveria a criminalidade, posicionando-se contrário ao seu rebaixamento, há quem assegure que não se trata de cláusula pétrea, não sendo um direito individual como garantia fundamental protegida pela impossibilidade de mudança.

30 L. O. D. Leal. A redução da idade de imputabilidade penal e seus aspectos constitucionais. Revista da Emerj. 2003. Pág. 263.

31 P. Lenza. Direito constitucional esquematizado. 15 ed. Pág. 762-763. Ed., Saraiva. (2012)
[...] Entendo que não constitui regra pétrea não por não estar incluído no art. $5^{\circ}$ da Constituição Federal, referente aos direitos e garantias individuais mencionados no art. 60, IV, da Constituição. Não é regra pétrea, pois não se trata de um direito fundamental ser reputado penalmente inimputável até completar dezoito anos. A medida foi adotada pelo Código Penal e depois pela Constituição Federal em face do que se avaliou como necessário e conveniente, tendo em vista atender aos interesses do adolescente e da sociedade. ${ }^{32}$

Com base nessa reflexão, historicamente, a inimputabilidade penal tem intenção específica de valorizar e proteger o indivíduo, ao conferir-lhe tratamento a partir de uma política criminal condizente com a realidade em que a juventude está inserida. Assim, o processo histórico do desenvolvimento da sociedade requer medidas urgentes do Estado para reparar as injustiças causadas pela violência ocasionada pelos jovens, inseridos no mundo do crime, que aderem cada vez mais conscientes das consequências de seus atos. Sabendo-se que a inimputabilidade penal não se reveste de caráter pétreo, posto não figurar no rol dos direitos fundamentais. Com a redução da maioridade penal não se aboliria um direito individual, tão somente estaria restringindo-se um patamar etário inserido por meio de uma opção de política criminal, não havendo ofensa a uma garantia expressa do texto constitucional.

Entrementes, o Código Penal remete-se à década de 1940, contexto histórico em que a situação social, política e econômica do país não representava avanços significativos para o desenvolvimento da sociedade, o que influenciava no processo de maturidade dos menores devido à falta de informação, realidade profundamente diversa do período moderno com as transformações do mundo globalizado da comunicação em tempo real.

Os crimes praticados por jovens são cada vez mais frequentes e comuns. Porém, estes crimes não são praticados apenas pelos excluídos e sem perspectivas. Um estudo realizado pela Udemo, o Sindicato de Especialistas de Educação do Magistério Oficial do Estado de São Paulo, mostrou que, em 1999, 89\% das escolas públicas registraram algum tipo de violência. Dos casos analisados, $21,28 \%$ foram de mortes de estudantes e $35,46 \%$ de ameaças de homicídio. Muitos desses jovens são carentes, porém o fato de frequentarem a escola mostra que

32 M. Reale Júnior. Instituições de Direito Penal: parte geral. 3. ed. Pág. 213. Ed., Forense. (2009). 
eles têm alguma perspectiva de mudança e adaptação à sociedade. ${ }^{33}$

Por meio de um levantamento sobre a violência realizado pela Secretaria de Pesquisa de Opinião Pública, Data Senado, para analisar em consulta pública a questão da redução da maioridade penal, dentre todos os entrevistados, verificou-se que 36\% declararam já terem sido vítimas de violência. Assim como $77 \%$ foram vítimas de roubo e $7 \%$ afirmaram ter perdido um parente ou conhecido vítima de homicídio, sendo todos os crimes praticados por menores de idade. Diante disso, 36\% acreditam que os jovens devem adquirir a maioridade penal aos 16 anos, de modo que outros $29 \%$ afirmam que desde os 14 anos os jovens devem ser responsabilizados criminalmente. E ainda $21 \%$ defendem punição a partir dos 12 anos, bem como para os demais $14 \%$ declaram que não deveria existir maioridade penal, devendo o infrator ser punido em qualquer idade. ${ }^{34}$

Atualmente, o acesso à informação possibilita aos jovens o amadurecimento intelectual precocemente, que com os avanços tecnológicos, com o uso da televisão, da internet e de tantos outros meios de comunicação propiciam uma realidade sociocultural que supera a concepção antiga da imputabilidade penal, a partir dos dezoito anos de idade. E essa situação releva que “[...] a revolta comunitária configura-se porque o ECA é muito tolerante com os jovens e não intimida os que pretendem transgredir a lei" ${ }^{35}$, uma vez que o artigo $121, \S 3^{\circ}$, do estatuto menorista prevê o período máximo de internação de três anos para os menores infratores em estabelecimentos correcionais.

O Estatuto da Criança e do Adolescente (ECA) é um afronto jurídico, e principalmente, um atentado à justiça social. Tal Estatuto incentiva a criminalidade através da impunidade dos criminosos menores de idade, já que o ECA tem o despudor de proibir a divulgação de seus nomes, e que suas fotos só podem ser estampadas mediante uma tarja de proteção. ${ }^{36}$

33 A. Kaufman. Maioridade Penal. Revista de Psiquiatria Clínica. 2004. Pág. 106.

34 Brasil. Senado Federal. Secretaria de Pesquisa e Opinião Pública. Pesquisa de opinião pública nacional: Violência no Brasil. (2007).

35 L. A. M. Ferreira. Direito da criança e do adolescente. 2 ed. Pág. 14. Ed. Lumarte. (2001).

36 F. Capez. Direito Penal: parte geral, v. I. 15. ed. Pág. 49. Ed. Saraiva. (2012).
A evolução da sociedade insere os jovens em um mundo capaz de eles terem consciência mais cedo do caráter ilícito de suas condutas. A par dessa reflexão, as medidas socioeducativas estabelecidas pelo ECA não têm diminuído a criminalidade, estando o Brasil entre um dos poucos países em que a inimputabilidade penal ainda é mantida até os 18 anos. Não se pode duvidar que a periculosidade dos crimes praticados pelos adolescentes é a mesma dos delitos cometidos pelos adultos diante da capacidade de discernimento para entender o caráter ilícito de sua conduta delitiva. Como consequência, verifica-se que os menores são facilmente aliciados para práticas criminosas pelos maiores, que planejam com isso ficar isentos da responsabilidade penal, estando à lei penal brasileira atrasada em relação à de outros países. Dessa feita, a impunidade apresenta-se com uma das principais causas do aumento da violência juvenil, sendo unânime a visão de que os menores não devem ficar impunes, devendo submeter-se à persecução da legislação criminal. Caso contrário, seria um estímulo à prática de delitos, sabendo os menores que nada pode lhes ocorrer em razão da possibilidade de eles não serem responsabilizados penalmente pelos crimes praticados.

\section{Pobre massa encarcerada}

Um dos resultados da influência da política de bem-estar social do século xx (que preconizou que a economia era o principal instrumento de transformação para viabilizar o desenvolvimento), gerou uma sociedade desigual e repleta de contrastes sociais, incapaz de resolver os problemas decorrentes da flexibilização da economia e desmantelamento do Estado, reordenando o mundo globalizado, conjugando violência, insegurança e medo, nutrindo o estigma da criminalização da pobreza. A precarização das relações sociais revela que a sociedade de consumo produz a marginalização de milhões de pessoas, que a partir de uma política estatal de controle social perverso das classes marginalizadas, confina-as em um mesmo espaço físico e geográfico, que das periferias são condenados a viver uma existência desumana dentro das prisões. Revelando que "[...] o caráter antissocial e coercitivo do Estado, hoje exacerbado, não é exclusivo dele. Em verdade, esse caráter é gestado na sociedade, isto é, nas relações econômicas e políticas de exploração do trabalho pelo capital e na 
luta incessante da burguesia pelo domínio do poder." ${ }^{{ }^{37}}$ Nessa perspectiva:

As periferias e as prisões pertencem ao mesmo tipo de organização, ambas são criadas para aprisionar o pobre, são instituições de confinamento forçado. As periferias e as favelas são prisões sociais, ao passo que as prisões são favelas judiciárias [...]. Ambas têm por missão confinar uma população estigmatizada de modo a neutralizar a ameaça material e/ou simbólica que ela faz pesar sobre a sociedade mais ampla, da qual ela foi extirpada [...]. Assim, recuperada a sua missão histórica de origem, o encarceramento, serve antes de tudo, para regular, senão, perpetuar, a pobreza e para armazenar os dejetos humanos do mercado. ${ }^{38}$

A expansão da política do encarceramento em massa no mundo surgiu com mais força nos Estados Unidos durante o período dos anos 1980, depois da queda da economia americana no governo Reagan, entre 1981 a 1988. Com o desmantelamento do Estado do bem-estar social, verificou-se o endurecimento do aparato repressivo contra a criminalidade crescente, dando início a uma política do aumento do efetivo policial, com o consequente crescimento da população carcerária. Aguardavam na lista de execução nas prisões americanas 2.802 pessoas, das quais eram afro-americanas 1.102 , oriundas das classes pobres. ${ }^{38}$

Essa indústria da prisão que desencadeou o fenômeno do encarceramento em massa empreendeu-se desde 1973 nos Estados Unidos, ocorrendo crescimento da população carcerária americana nunca vista antes na história dos países democráticos. Dessa feita, em 1995, a população era de 5,4 milhões de encarcerados e a partir de 2003 tornava-se de aproximadamente 6,9 milhões de pessoas, situação muito distinta do período de 1985 que era de 3 milhões, sendo há dez anos antes de apenas um milhão de pessoas sob a tutela penal.

O mais impressionante é constatar-se que em 1995 a cada dez homens encarcerados um era negro, e os índices relacionados às pessoas afro-americanas em 1993, tornara-se dez vezes superior aos de origem europeia, e isso leva a compreender que a justiça criminal americana revestia-se de um mecanismo de controle

37 P. A. P. Pereira. Do Estado social ao Estado antissocial. Em P. A. P. Pereira ET AL. Política social, trabalho e democracia. Ed., Universidade de Brasília. Programa de Pós-graduação em Política Social. (2009).

38 L. Wacquant. Punir os pobres: a nova gestão da miséria nos Estados Unidos. Pág. 126; 335. ed. 3. Ed. Revan. (2007). social com base na dominação racial. Essa realidade do sistema repressivo adotado nos EUA dava-se, possivelmente, pelos crescentes níveis de criminalidade e da violência contra a pessoa. Contudo, dados verificados a partir de estatísticas criminais revelavam que se estabilizaram os índices entre a década de 1970 ou diminuíram até os anos 1990, de maneira que a mudança que houve na política penal americana "não foi a frequência e o caráter da atividade criminal, mas a atitude das autoridades face à delinquência e a sua principal fonte, a miséria urbana concentrada nas grandes metrópoles." ${ }^{39}$

No Brasil, é relevante ser mencionado que com a possibilidade da redução da maioridade penal seria inevitável a inserção dos menores de 18 anos no atual sistema prisional degradante, ao não haver quaisquer condições para garantir-se a ressocialização e consequente reinserção dos jovens na sociedade. No sistema penitenciário brasileiro, o crime organizado está instalado e as organizações criminosas desfrutam de benefícios entre os detentos, de acordo com o poder que os chefes de facções detêm, comandando as quadrilhas de dentro das próprias unidades prisionais, constituindo-se de verdadeiras "escolas do crime". A superlotação das celas, o convívio em um ambiente precário de condições de higiene, propicia um estabelecimento predisposto à proliferação de epidemias e contágio de doenças. Essa convivência de um amontoado de pessoas associada à precariedade e insalubridade das prisões, à péssima alimentação dos presos, sedentarismo e uso de drogas, integram fatores estruturais que não preservam as garantias fundamentais do cidadão e as garantias do homem preso. A atual situação do sistema prisional brasileiro impossibilita o cumprimento da sanção penal quando não atende a sua finalidade humanizadora, preconizada pelo novo modelo de execução trazido pela Lei de Execuções Penais, não provendo as condições necessárias para a harmônica integração social do condenado, tornando-se um atentado ao princípio constitucional da dignidade da pessoa humana. Existe, atualmente, um déficit de vagas no sistema penitenciário, não considerando os mandados de busca e apreensão que estão sem execução, que inevitavelmente aumentaria sobremaneira o número de detentos nos estabelecimentos prisionais. É importante considerar que seria inadmissível lançar adolescentes em meio a este contingente que vivencia toda sorte de violações dos direitos humanos.

39 L. Wacquant. Crime e Castigo nos Estados Unidos: de Nixon a Clinton. Revista de Sociologia Política. novembro, 1999. Pág. 39-50. 
Em razão dessa conjunção de fatores negativos, a deflagração de rebeliões e fuga de presos é um problema constante no sistema prisional. Perante a falta de segurança nos presídios, os levantes violentos revelam-se como uma alternativa de reivindicação de seus direitos, conclamando-se a atenção das autoridades públicas para a falência do sistema prisional. Nesse prisma, "[...] a imensa maioria dos protestos reivindicatórios massivos produzidos na prisão tem sua origem nas deficiências efetivas do regime penitenciário. As deficiências são tão graves, que qualquer pessoa que conheça certos detalhes da vida carcerária fica profundamente comovida." ${ }^{40}$ A pena privativa de liberdade deve cumprir o seu caráter ressocializador, efetivando-se as garantias legais e constitucionais, visando-se à concretização dos direitos fundamentais dos condenados, sobretudo, considerando-se que cerca de $95 \%$ da população encarcerada é proveniente das camadas sociais excluídas, constituída de pobres, desempregados e analfabetos, entregues às condições subumanas dentro das prisões. Em um Estado Democrático de Direito é fundamental a efetivação do corolário constitucional da dignidade da pessoa humana, tornando-se inadmissível tratamento desigual entre os cidadãos dotados de mesma dignidade. O sistema prisional brasileiro atualmente é reflexo da falta de interesse da sociedade e do Estado, não cumprindo com o dever de salvaguardar tratamento digno ao detento. Reconhecer isso é um passo inicial para que o poder público extinga as condições deteriorantes do cárcere.

\section{CONCLUSÃo}

Buscamos demonstrar que, em parte, a política econômica adotada internacionalmente favorece a grande concentração de riquezas, provocando profundas desigualdades sociais, provocando estigmatização da massa empobrecida, ocorrendo à deflagração ideológica pela mídia, que relaciona a criminalidade com a pobreza, gerando medo e insegurança na sociedade. No Brasil, a pobreza quase sempre está associada à criminalidade que se localiza nas periferias das grandes cidades, a qual sobrevive com a falta de políticas públicas e precárias condições de vida, e atinge crianças e adolescentes. Além disso, "pobre, negro e analfabeto" têm sido a cara da criminalidade brasileira. Esse perfil

40 S. de. Carvalho. Penas e Garantias. 3. ed. Pág. 234. Ed. Lumen Juris. (2008). representa a face oculta de um processo de sociabilidade profundamente excludente, que se instalou dentro de uma mesma nação. Revela a triste consequência de um desenvolvimento econômico desumano, que visa somente ao acúmulo de capital que se processa pela ideologia de um mercado de consumo.

A defesa da redução da imputabilidade penal como alternativa punitiva e repressora, propagada pela mídia como solução para reverter a situação de insegurança urbana, é hoje considerada uma política criminal bastante aceita pela sociedade para a penalização da delinquência juvenil. Como consequência, não se elabora uma discussão séria e aprofundada do tema da criminalidade, desconsiderando as consequências nefastas da inserção de crianças e adolescentes no falido sistema prisional que, além de não ressocializar, tornase o local das piores violações dos Direitos Humanos.

Ademais, os direitos e garantias individuais foram insculpidos como cláusula de imutabilidade em razão da sua relevância como pilares de sustentação da vontade da soberania popular na criação do Estado Democrático de Direito. O artigo 228 da Constituição Federal ao prever tratamento diferenciado às crianças e aos adolescentes considerou as peculiaridades de um grupo de indivíduos em processo contínuo de desenvolvimento psíquico, e conferiu-lhes proteção integral participando a sociedade, o Estado e a família.

$\mathrm{O} \$ 4^{\circ}$ do inciso IV, do artigo 60 da Constituição, necessita para a sua adequada concretização a atuação do intérprete diante da sua inexatidão da expressão direitos e garantias individuais, sobretudo, para a inclusão de direitos fundamentais no sistema disperso de direitos verificados pelo $\$ 2^{\circ}$ do artigo $5^{\circ}$. Por isso, a inimputabilidade penal aos menores de dezoitos anos tem a intenção específica de valorizar e proteger o indivíduo que revela uma opção do legislador constituinte de oferecer-lhes um tratamento de caráter fundamental, sendo insusceptível de qualquer tentativa de modificação por legislação infraconstitucional ou por meio de emenda constitucional. É preciso que a violência que envolve jovens seja analisada a partir de um contexto mais amplo, bem como se considere que a inimputabilidade penal aos menores de dezoito anos encontra-se protegida constitucionalmente como direito fundamental inviolável.

Para o enfrentamento da criminalidade juvenil, é preciso que o Estado e a sociedade implementem políticas públicas de inclusão social promovendo a ressocialização do menor de acordo com práticas pedagógicas preconizadas por medidas socioeducativas, que se revelem eficazes para a reinserção dos jovens na sociedade. 


\section{REFERÊNCIAS}

A. Barata. Criminologia crítica e crítica do direito penal: introdução à sociologia do direito penal. Tradução Juarez Cirino dos Santos. 3. ed. Pág. 119. Ed. Revan. (2002).

A. Kaufman, Maioridade Penal. Revista de Psiquiatria Clínica. 2004. Pág. 106.

A. Moraes. Constituição do Brasil interpretada e legislação constitucional. 8. ed. Pág. 2.036. Ed. Atlas. (2012).

A. Queirós. Por que não à redução da idade penal? In: Fórum permanente de entidades não-governamentais de defesa dos direitos da criança e do adolescente. Infância, ato infracional e cidadania. Pág. 31. Ed. Inesc. (1999).

A. R. Tavares. Curso de direito constitucional. 9. ed. Pág. 54. Ed. Saraiva. (2011).

B. Cleinman. Mídia, crime e responsabilidade. Revista de Estudos Criminais. 2001. Pág. 97. www.itecrs.org/revista/1.pdf. (10 abril 2011).

Baierl. L. F. Medo social: da violência visível ao invisível da violência. São Paulo: Cortez, 2004.

Brasil. Convenção internacional sobre os direitos da criança. 2008. Disponível em: <http://www.mpmg.gov. br.extranet/visao/sigecon/html/uploads/html_proprio/ html_7621/>. Acesso em: 16 nov. 2011.

Brasil. Senado Federal. Secretaria de Pesquisa e Opinião Pública. Pesquisa de opinião pública nacional: Violência no Brasil. (2007).

Brasil. Vade Mecum Saraiva. 6. ed. Pág. 74. Ed. Saraiva. (2012).

E. L. E. Silva. De beccaria a filippo gramatica: ciência e política criminal em honra de Heleno Fragoso. Pág. 23. Ed. Forense. (1993).

E. R. Zaffaronni. Em busca das penas perdidas: a perda de legitimidade do sistema penal. Pág. 131. Ed. Revan. (1991).

F. Capez. Direito Penal: parte geral, v. I. 15. ed. Pág. 49. Ed. Saraiva. (2012).

F. Piovesan. A inconstitucionalidade da redução da maioridade penal. www.direitocriminal.com.br. (16 de outubro 2011).

G. F. Mendes. Os Limites da Revisão Constitucional. Revista Notícia do Direito Brasileiro. 1996. Pág. 188.

G. R. M. M. Simões. A redução da idade de responsabilidade penal solucionaria o problema da violência? Revista Jurídica da Universidade de Franca: Unifran. maio 2001. Pág. 79.

Guareschi, P. A. et al. Os construtores da informação: meios de comunicação, ideologia e ética. 2. ed. Pág. 43. Ed. Vozes. (2007).

J. B. C. Saraiva. A idade e as razões: não ao rebaixamento de imputabilidade penal. Revista Brasileira de Ciências Criminais. abril-junho 1997. At. Pág. 91.
J. B. Thompson. A mídia e a modernidade: uma teoria social da mídia. 11. ed. Pág. 54. Ed. Vozes. (2009).

J. F. Mirabete. Manual de direito penal: parte geral, v. 1.27 ed. Pág. 217. Ed. Atlas. (2012).

J. J. Waiselfisz. Mapa da violência IV: os jovens do Brasil. Pág. 73. Ed. Unesco, Instituto Airton Senna. Secretaria Especial dos Direitos Humanos. (2004).

L. A. M. Ferreira. Direito da criança e do adolescente. 2 ed. Pág. 14. Ed. Lumarte. (2001).

L. O. D. Leal. A redução da idade de imputabilidade penal e seus aspectos constitucionais. Revista da EMERJ. 2003. Pág. 263.

L. Wacquant. Crime e Castigo nos Estados Unidos: de Nixon a Clinton. Revista de Sociologia Política. novembro, 1999. Pág. 39-50.

L. Wacquant. Punir os pobres: a nova gestão da miséria nos Estados Unidos. Pág. 126; 335. ed. 3. Ed. Revan. (2007).

M. A. Geske. Imputabilidade do Adolescente no Direito Penal. Revista da ESMESC. 2007. Pág. 226.

M. C. Alvarez. Menoridade e delinquência: uma análise do discurso jurídico e institucional da assistência e proteção aos menores no Brasil. Cadernos da FFC (Unesp). 1997. Pág. 24.

M. Reale Júnior. Instituições de Direito Penal: parte geral. 3. ed. Pág. 213. Ed. Forense. (2009).

M. S. da Campos. Mídia e política: a construção da agenda nas propostas de redução da maioridade penal na câmara dos deputados. Opinião Pública. novembro, 2009. Pág. 478509. http://www.scielo.br/scielo.php?pid=S0104-62762 009000200008\&script=sci_arttext. (17 novembro 2011).

M. Volpi. Sem liberdade, sem direitos: a privação de liberdade na percepção do adolescente. Ed. Cortez. (2001).

N. Slaib Filho. Direito Constitucional. Pág. 379. Ed. Forense. (2004).

P. A. P. Pereira. Do Estado social ao Estado antissocial. Em P. A. P. Pereira ET AL. Política social, trabalho e democracia. Ed. Universidade de Brasília. Programa de Pósgraduação em Política Social. (2009).

P. Lenza. Direito constitucional esquematizado. 15 ed. Pág. 762-763. Ed. Saraiva. (2012).

Rebelo, C. E. B. Maioridade penal e a polêmica acerca de sua redução. Pág. 22. Ed. Ius Editora. (2010).

S. de. Carvalho. Penas e Garantias. 3. ed. Pág. 234. Ed. Lumen Juris. (2008).

S. Moretzsohn. O caso Tim Lopes: o mito da "mídia cidadã". www.bocc.ubi.pt/pag/moretzsohn-sylvia-tim-lopes. pdf. (25 março 2011). 